\title{
Analytical Management of Patients Undergoing Oral Anticoagulant Therapy Could Have a Strong Impact on Clinical Outcomes: A Follow-up Study
}

\author{
Vincenzo De Iuliis · Sebastiano Ursi · Gianfranco Vitullo • \\ Irma Griffo · Antonio Marino - Marika Caruso - Francesco Cipollone • \\ Sabrina Capodifoglio • Veronica Breda • Elena Toniato • \\ Alfonso Pennelli · Pio Conti · Stefano Martinotti
}

Received: March 8, 2017 / Published online: May 19, 2017

(C) The Author(s) 2017. This article is an open access publication

\begin{abstract}
Introduction: Oral anticoagulant therapy, such as vitamin $\mathrm{K}$ antagonists (VKAs), is prominent for the prevention of cerebral ischemic stroke or systemic embolism and all-cause mortality in patients with atrial fibrillation, venous thromboembolism, and mechanical or biological valve. VKA treatment requires monitoring of the international normalized ratio (INR) in order to maintain it in a therapeutic range, avoiding side effects, the main and most significant of which is bleeding. The aim of the present study was to evaluate the event rates of
\end{abstract}

Enhanced content To view enhanced content for this article go to http://www.medengine.com/Redeem/ CD08F0601C9691C1.

V. De Iuliis · S. Ursi · G. Vitullo · I. Griffo ·

A. Marino $\cdot$ S. Martinotti

CHIETI, SS Annunziata University Hospital,

ASL Lanciano-Vasto-Chieti, University of Chieti,

Via dei Vestini 31, 66100 Chieti, CH, Italy

V. De Iuliis · A. Marino - M. Caruso ·

S. Capodifoglio $\cdot$ V. Breda $\cdot$ E. Toniato $(\bowtie)$.

A. Pennelli · P. Conti . S. Martinotti

Department of Medical, Oral and Biotechnological

Sciences, University of Chieti, Via dei Vestini 31,

66100 Chieti, $\mathrm{CH}$, Italy

e-mail: e.toniato@unich.it

F. Cipollone

Department of Medicine and Science of Aging,

University of Chieti, Via dei Vestini 31,

66100 Chieti, CH, Italy several clinical composite outcomes, such as bleeding, thromboembolic events, and all-cause death.

Methods: We compared three organizational models distinguished by a total (from 1 January to 31 December 2015 in which PT/INR analysis with the relative internal and external quality controls was performed by the surveillance center) or partial (from 15 January to 15 July 2016 and from 15 August to 15 November 2016, in which the surveillance center had the ability to view only the PT/INR results or all patients analyses, including blood count, creatinine, liver enzymes, etc., respectively) analytical patient management. The present longitudinal follow-up study included 1225 patients, recruited from 1 January 2015 to 15 November 2016 at a surveillance center for the prevention of cerebral ischemic stroke and systemic embolism in Chieti (Italy).

Results: The results show a significant rise of the incidence rate ratio in patients undergoing VKA treatment during the period 15 January to 15 July 2016 compared to the previous one regarding total bleeding, especially for minor bleeding and digestive bleeding; thromboembolic events; and all-death cause.

Conclusions: These findings show that analytical and clinical data and information should be under the direct supervision and responsibility of the surveillance center. In fact, this approach seems to highlight the best results in terms of safety and therapeutic effectiveness. 
Keywords: Atrial fibrillation; Bleeding risk; Clinical outcomes; Oral anticoagulant

\section{INTRODUCTION}

Oral anticoagulant therapy, such as vitamin $\mathrm{K}$ antagonists (VKAs), is prominent for the prevention of cerebral ischemic stroke or systemic embolism and all-cause mortality in patients with atrial fibrillation (AF) and one or more risk factors for stroke [1-4]. Atrial fibrillation is the most common cardiac arrhythmia managed in clinical practice and the most common arrhythmia requiring hospitalization [5-7]. Thromboembolism also occurs with similar incidence $[8,9]$. Anticoagulation with warfarin, at a target international normalized ratio (INR), has consistently been shown to reduce the risk of cerebral ischemic stroke, a major goal of therapy for AF [10-12]. Oral anticoagulants are also frequently administrated for other indications, ranging from venous thromboembolism to mechanical prosthetic heart valves [13]. In order to determine who should receive anticoagulation therapy, a risk-stratification model is used [14]. The rationale behind risk stratification is that, although anticoagulation has clearly been shown to be more effective than antiplatelet agents or placebos in the prevention of thromboembolic stroke, their use should be restricted to patients whose risk for a thromboembolic event exceeds their risk of hemorrhage [15-17]. Placebos are obsolete for the treatment of cerebral ischemic stroke [18]. An initial score called $\mathrm{CHADS}_{2}$ included the following risk factors for thromboembolic events in non-valvular AF: (i) a history of cerebral ischemic stroke, (ii) diabetes mellitus, (iii) hypertension, (iv) heart failure, and (v) age [19-24]. A subsequent score, known as $\mathrm{CHA}_{2} \mathrm{DS}_{2}$-VASc, was developed to further determine the risk in the low-risk groups using the following risk factors: (i) age, (ii) sex, (iii) congestive heart failure, (iv) hypertension history, (v) stroke/TIA/thromboembolism history, (vi) vascular disease history, (vii) diabetes history $[25,26]$. The major bleeding risk was evaluated using the HAS-BLED score, consisting of the following risk factors: (i) hypertension, (ii) renal disease, (iii) liver disease, (iv) cerebral ischemic stroke history, (v) prior major bleeding or predisposition to bleeding, (vi) labile INR, (vii) age greater than 65 years, (viii) medication usage predisposing to bleeding, (ix) alcohol or drug usage history [27]. Warfarin dosing is targeted to a therapeutic INR, which is usually 2-3 in $\mathrm{AF}$, but may be higher, 2.5-3.5, for mechanical mitral valves [27]. Numerous medications interact with warfarin and affect its metabolism. For these reason, VKA treatment requires monitoring of the INR in order to maintain it in a therapeutic range, avoiding some side effects, the major and most significant of which is bleeding [27]. In fact, as already reported, an over-anticoagulation leads to significant risk of bleeding when the INR is greater than 3 [28]. The aim of the present longitudinal follow-up study was to evaluate the event rates of several clinical composite outcomes, such as bleeding, thromboembolic events, and all-cause death, comparing three organizational models of the analytical patient management, on the basis of a centralized or a local control of the PT/ INR $[29,30]$. In particular, in the first group the PT/INR test was performed and controlled by the surveillance center; in the second and third one the center did not have the possibility to perform the PT/INR test, but had only the ability to view the PT/INR results or all patients analyses, respectively. The present investigation was necessary to evaluate the best analytical organizational model for patients undergoing VKA therapy.

\section{METHODS}

\section{Study Subjects}

The Medical Research Ethics Committee of the SS Annunziata University Hospital of Chieti, Italy, approved the study and patients gave their written informed consent to participate. Investigations were performed in accordance with the Declaration of Helsinki. In this longitudinal follow-up study, a total of 1225 patients, recruited from 1 January 2015 to 15 November 2016 at a surveillance center for the prevention of cerebral ischemic stroke and 
systemic embolism in Chieti (Italy) were involved. All patients were divided into three groups as follows: (1) 954 patients recruited from 1 January to 31 December 2015; (2) 966 patients from 15 January to 15 July 2016; (3) 1024 patients from 15 August to 15 November 2016. The inclusion criteria were the presence of at least one of the following diseases which necessitate anticoagulant therapy: (i) atrial fibrillation; (ii) venous thromboembolism; (iii) mechanical or biological valve; (iv) artheriopathy; (v) valvular disease. These patients received an oral anticoagulant (OAC) therapy using VKAs, such as Coumadin $5 \mathrm{mg}$ or Sintrom $4 \mathrm{mg}$, with dose adjustment during the follow-up.

\section{Study Design}

In this study, three organizational models in the analytical management were evaluated. Specifically, regarding the first organizational model, from 1 January to 31 December 2015, the analytical management of patients treated with VKAs was under the direct responsibility of the Chieti surveillance center [e.g., PT/INR analysis with the relative internal and external quality controls was performed by the surveillance center; it was given the possibility to access the laboratory information system, and then to all patients laboratory analyses (e.g., blood count, serum creatinine, liver enzymes, many useful for the correct VKAs administration)]. Indeed, after a hospital reorganization in the management of patients undergoing anticoagulant therapy from 15 January to 15 July 2016, the surveillance center used a second organizational model, which provided the ability to view only the PT/INR results of the patients (not all laboratory analyses). The center did not have the possibility to perform the PT/INR tests and to evaluate the internal and external quality controls and therefore the quality of the results, necessary for the administration of the anticoagulant therapy. Subsequently, access to the laboratory information system was given between 15 August and 15 November, and patients underwent a third organizational model in which the surveillance center had the possibility to monitor all laboratory analyses, without the capacity to perform the PT/INR tests and to evaluate the internal and external controls. However, for the entire period of the study, the same physicians of the surveillance center performed a correct therapeutic dosage using computer-assisted tools (using the following software: PARMA5, IL-WERFEN, Milan, Italy; PROMETEO, Siemens, Munich, Germany).

\section{Clinical Outcomes Investigated}

The primary endpoint of the study was to evaluate the incidence rates of the following clinical outcomes: bleeding, thromboembolic events, and all-cause death. The hemorrhagic events were also distinguished in terms of major and minor bleeding: major bleeding was characterized by (i) fatal bleeding or symptomatic bleeding in a critical area or organ, such as intracranial, intraspinal, intraocular, retroperitoneal, intra-articular or pericardial, or intramuscular with compartment syndrome, and/or (ii) bleeding causing a fall in hemoglobin level of $20 \mathrm{~g} / \mathrm{L}(1.24 \mathrm{mmol} / \mathrm{L})$ or more, or (iii) leading to transfusion of two units of packed red blood cells; minor bleeding included all other types of bleeding (e.g., digestive bleeding, epistaxis, hematuria, conjunctival hemorrhage without the characteristics of major bleeding) [31]. The thromboembolic outcome included symptomatic cerebral ischemic stroke, TIA, venous thromboembolism, and systemic embolism. All-cause and cardiovascular deaths were also determined. The diagnostic criteria for each event have been described elsewhere [32].

\section{Statistical Analysis}

The parameters analyzed for the three periods were the incidence rate for 100 person time units (IR\%: number of events/person years $\times 100$ ); the incidence rate ratio compared to the 2015 group (IRR); the percentage of increase or decrease of incidence rate ratio compared to the 2015 group [\% of increase/decrease IRR: (incidence rate ratio -1 ) $\times 100$ ]; the incidence rate difference for 100 person time units compared to the 2015 group [IRD\%: (incidence rate 2016 -incidence rate 
2015) $\times 100$ ]; and the attributable risk compared to the 2015 group (AR: incidence rate difference for 100 person time units/incidence rate 2016 for 100 person time units $\times 100$ ). In order to evaluate a significant difference for the incidence rate ratio and the incidence rate difference between the three organizational models, an exact Fisher and a McNemar's test were used, respectively (Stat View 4.0 software, Abacus Concepts, Berkeley, CA, USA). $P$ values less than 0.05 were considered statistically significant, with a confidence interval of $95 \%$. The sample size calculation formula, previously described [33], showed that the number of patients per arm should be at least 377 .

\section{RESULTS}

\section{Clinical Features}

Demographic and clinical patient characteristics are shown in Table 1 (age $76.05 \pm 12.1$; male $50.5 \%$, female $49.5 \%$ ). The treatment years of the 2015, Jan-Jul 2016, and Aug-Nov 2016 groups were 774.9, 372.8, and 190.8, respectively. Coumadin $5 \mathrm{mg}$ was the drug mostly prescribed $(95.9 \%)$. There was no significance difference in the therapeutic time in range between the three groups $(2015,69.4 \%$; Jan-Jul 2016, 68.8\%; Aug-Nov 2016, 70.5\%).

\section{Comparison of Incidence Rates and Incidence Ratio Regarding the Clinical End-Points Between the Three Different Organizational Models}

As shown in Figs. 1 and 2, the data evidenced a significantly increased number of all events occurring in patients during the period 15 January-15 July 2016 compared to the previous period (no. of cases 2015, 51; Jan-Jul 2016, 58. IR\% 2015, 6.58\% [CI 4.9-8.65]; IR\% Jan-Jul 2016, $15.56 \%$ [CI 11.81-20.12]. IRR, 2.36 [CI 1.62-3.46], $p<0.001)$. In particular, the data showed an increased number of the following events with an increasing rate of severity: minor bleedings (no. of cases 2015, 24; Jan-Jul 2016, 26. IR\% 2015, 3.1\% [CI 1.98-4.61]; IR\% Jan-Jul 2016, 6.98\% [CI 4.55-10.22]. IRR, 2.25 [CI 1.29-3.92],
Table 1 Patients' characteristics

\begin{tabular}{|c|c|c|c|c|}
\hline $\begin{array}{l}\text { Patients' } \\
\text { characteristics }\end{array}$ & $\operatorname{Max}$ & Min Mean & SD & Median \\
\hline \multirow[t]{2}{*}{ Age (years) } & 96 & 76.05 & 12.1 & 78 \\
\hline & \multicolumn{3}{|c|}{ Number } & $\%$ \\
\hline \multicolumn{5}{|l|}{ Sex } \\
\hline $\mathrm{F}$ & \multicolumn{3}{|c|}{618} & 50.5 \\
\hline M & \multicolumn{3}{|c|}{607} & 49.5 \\
\hline \multicolumn{5}{|l|}{ Disease } \\
\hline $\mathrm{AF}$ & \multicolumn{3}{|c|}{815} & 66.5 \\
\hline VTE & \multicolumn{3}{|c|}{199} & 16.2 \\
\hline Mechanical valve & \multicolumn{3}{|c|}{141} & 11.5 \\
\hline Artheriopathy & \multicolumn{3}{|c|}{31} & 2.5 \\
\hline Valvular disease & \multicolumn{3}{|c|}{23} & 1.9 \\
\hline Biological valve & \multicolumn{3}{|c|}{17} & 14 \\
\hline \multicolumn{5}{|l|}{ OAC } \\
\hline Coumadin $5 \mathrm{mg}$ & \multicolumn{2}{|r|}{1176} & & 95.9 \\
\hline Sintrom $4 \mathrm{mg}$ & \multicolumn{3}{|c|}{50} & 4.1 \\
\hline
\end{tabular}

\begin{tabular}{lcc}
\hline Group & \multicolumn{2}{c}{ Person years } \\
\hline 2015 & 774.9 & \\
Jan-Jul 2016 & 372.8 & \\
Aug-Nov 2016 & 190.8 & \\
\hline VKA effectiveness & \multicolumn{2}{c}{} \\
\hline TTR 2015 & 69.4 \\
TTR Jan-Jul 2016 & 68.8 \\
TTR Aug-Nov 2016 & & 70.5
\end{tabular}

Age, sex, the underlying pathology that required an anticoagulant therapy, the type of oral anticoagulant (OACs) prescribed, the division into the two groups, and the respective VKA effectiveness based on the management model applied to patients were described

$A F$ atrial fibrillation, $V T E$ venous thromboembolism, $V K A$ vitamin $\mathrm{K}$ antagonists, $T T R$ time in therapeutic range

$p<0.01$ ); venous thromboembolic events (no. of cases 2015, 4; Jan-Jul 2016, 8. IR\% 2015, 0.52\% [CI 0.14-1.32]; IR\% Jan-Jul 2016, 2.15\% [CI 


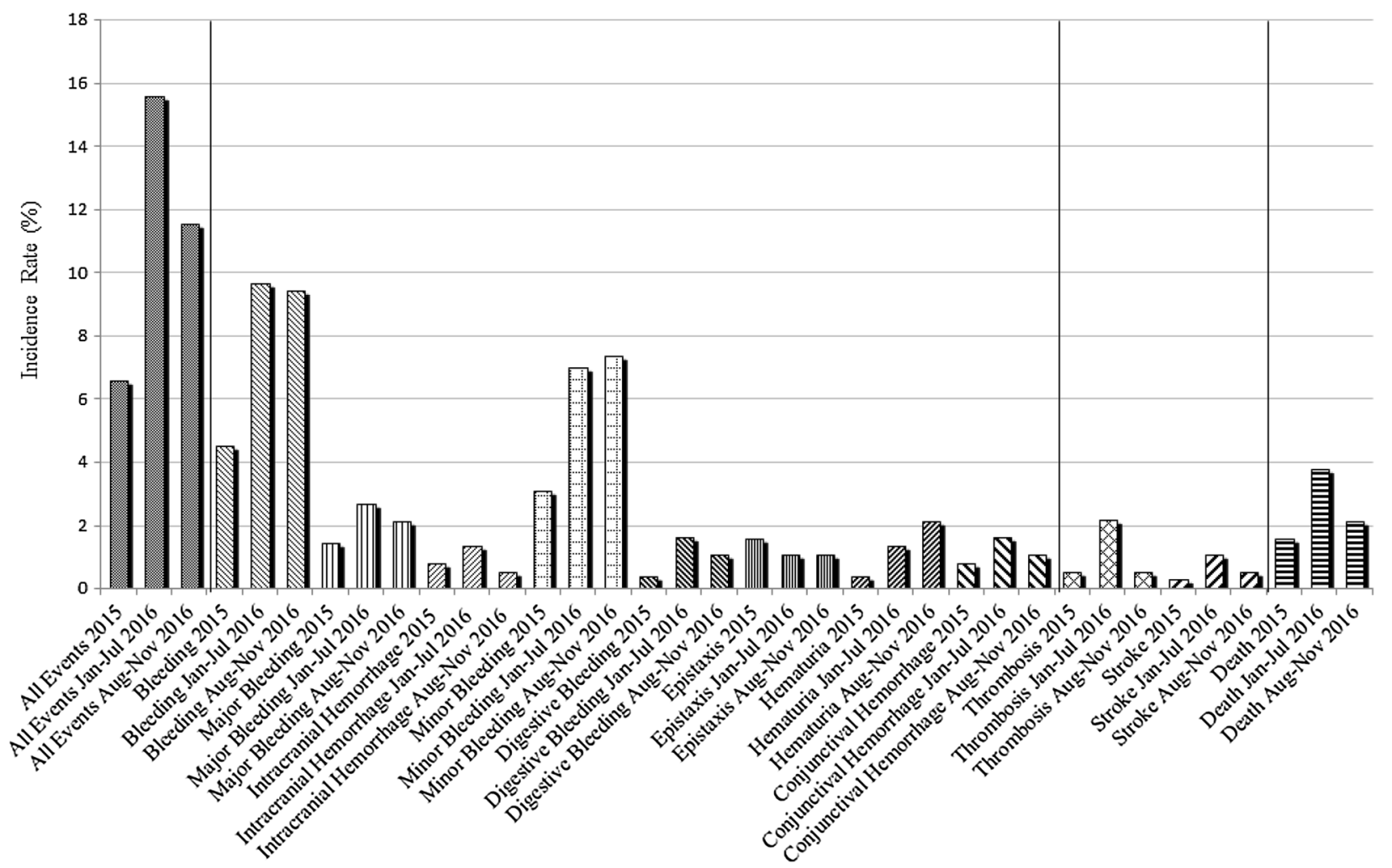

Fig. 1 Comparison of the two organizational models analyzing the patient clinical outcomes. The incidence rate among the several analytical management models is shown

0.92-4.23]. IRR, 4.16 [CI 1.25-13.81], $p<0.05$ ); major bleedings (no. of cases 2015, 11; Jan-Jul 2016, 10. IR\% 2015, 1.42\% [CI 0.7-2.54]; IR\% Jan-Jul 2016, 2.68\% [CI 1.28-4.93]. IRR, 1.89 [CI $0.8-4.45]$ ); cerebral ischemic stroke (no. of cases 2015, 2; Jan-Jul 2016, 4. IR\% 2015, 0.26\% [CI 0.03-0.09]; IR\% Jan-Jul 2016, $1.07 \%$ [CI 0.28-2.74]. IRR, 4.16 [CI 0.76-22.7]); all-cause deaths (no. of cases 2015, 12; Jan-Jul 2016, 14. IR\% 2015, 1.55\% [CI 0.8-2.7]; IR\% Jan-Jul 2016, $3.76 \%$ [CI 2.05-6.3]. IRR, 2.43 [CI 1.12-5.24], $p<0.05$ ). In addition, during the period Aug-Nov 2016 we observed an increased number of the majority of adverse events (except for epistaxis and intracranial hemorrhage) compared to the period Jan-Dec 2015 and, also, a decrease of the incidence rate ratio in particular with regard to major bleeding (no. of cases, 4), intracranial hemorrhages (no. of cases 1 ), venous thrombotic events (no. of cases, 1), cerebral ischemic strokes (no. of cases, 1), and the allcause deaths (no. of cases, 4), with respect to the Jan-Jul 2016/2015 rate ratio (Figs. 1, 2).

\section{Analysis of the Percentage Increase/ Decrease of the Incidence Rate Ratio}

As shown in Fig. 3, a percentage increase of the incidence rate ratio between the Jan-Jul 2016 and Aug-Nov 2016 organizational models as compared to the 2015 model was evidenced with regard to all events (Jan-Jul 2016, 136.4\%; Aug-Nov 2016, 75.2\%); minor bleedings (125.2\% and $136.9 \%)$; venous thromboembolic events (315.8\% and 1.6\%); major bleedings $(88.9 \%$ and $47.7 \%)$; cerebral ischemic stroke (315.8\% and $103.1 \%)$; all-cause deaths (142.5\% and $35.4 \%)$.

\section{Impact of the Three Organizational Patient Management Models on Clinical Outcomes}

The incidence rate difference (2016-2015) and the attributable risk were calculated to better understand the percentage of the increased 


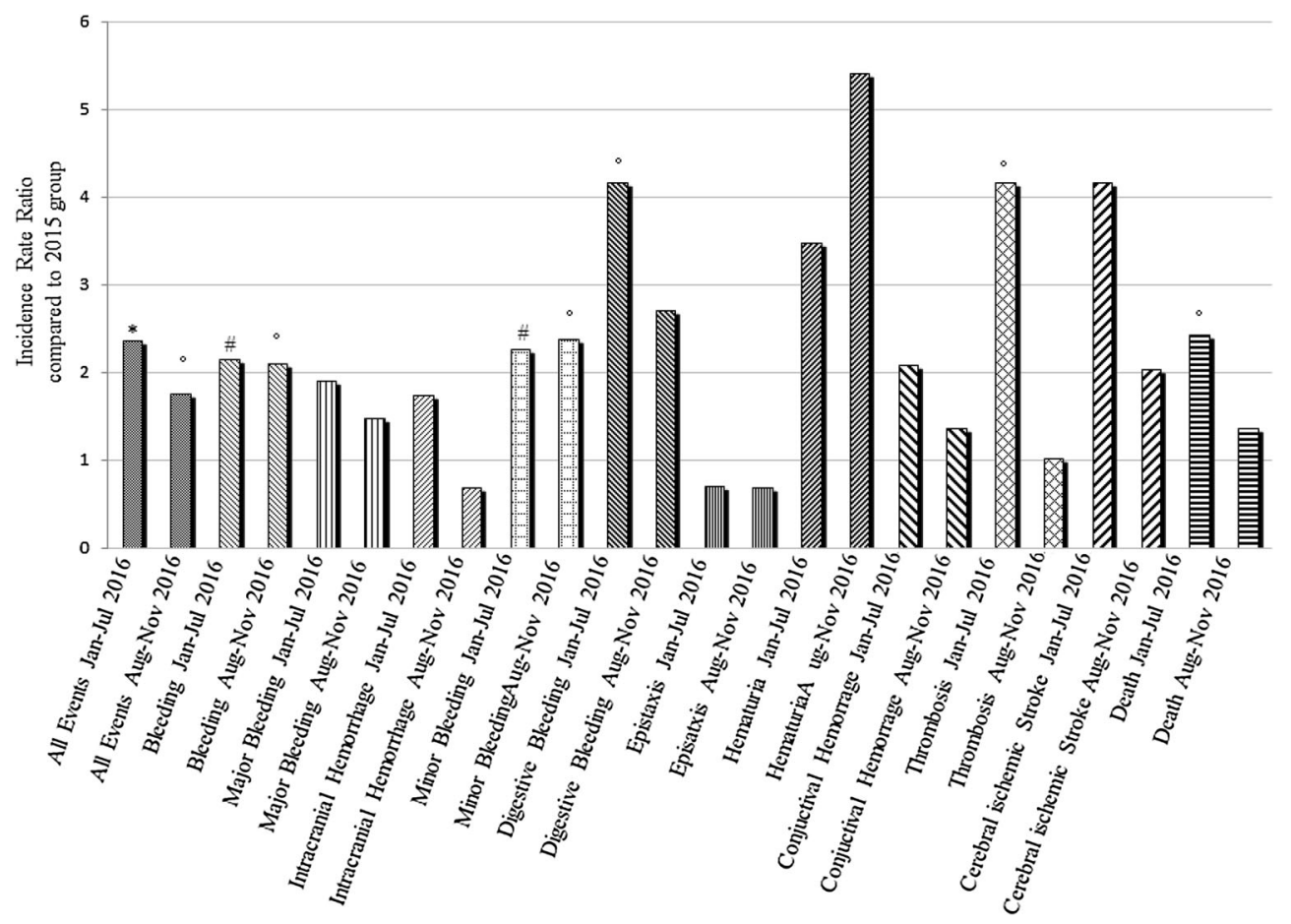

Fig. 2 Statistical analysis between the three organizational models regarding the incidence rate ratio between the 2016 groups, Jan-Jul and Aug-Nov, compared to the 2105 group. ${ }^{*} p<0.001 ;{ }^{\#} p<0.01 ;{ }^{\circ} p<0.05$

number of events attributable to the change in the organizational model. As shown in Figs. 4 and 5, the impact of this change was highly evident during the period Jan-Jul 2016 compared to the 2015 group for all events (IRD\%, 8.98\% [CI 4.59-13.37], $p<0.001$; AR, $57.7 \%$ ), minor bleedings (IRD\%, 3.88\% [CI 0.92-6.83], $p<0.01 ; \mathrm{AR}, 55.6 \%)$, venous thromboembolic events (IRD\%, 1.63\% [CI 0.59-3.2], $p<0.05$; AR, 75.9\%), major bleedings (IRD\%, $1.26 \%$ [CI -0.59 to 3.13]; $\mathrm{AR}$, $47.1 \%$ ), cerebral ischemic stroke (IRD\%, 0.82\% [CI -0.29 to 1.93 ]; AR, 75.9\%), all-cause deaths (IRD\%, 2.21\% [CI 0.54-4.36], $p<0.05$; $\mathrm{AR}, 58.8 \%)$. In addition we observed that there was no significant difference among the Aug-Nov 2016 and the 2015 groups for the following events: major bleeding (IRD\%, $0.68 \%$ [CI -1.5 to 2.9$]$; $\mathrm{AR}, 32.3 \%)$, venous thromboembolic events (IRD\%, 0.008\% [CI -1.1 to 1.15 ]; $\mathrm{AR}, 1.54 \%)$, cerebral ischemic stroke (IRD\%, $0.27 \%$ [CI -0.82 to 1.35$]$; AR, $50.7 \%$ ), all-cause deaths (IRD\%, 0.55\% [CI -1.68 to 2.78 ]; $\mathrm{AR}, 26.2 \%$ ).

\section{DISCUSSION}

Oral anticoagulant treatment is highly relevant for the prevention of cerebral ischemic stroke or systemic embolism and all-cause mortality in patients with atrial fibrillation and one or more risk factors for stroke [1-4]; on the other hand, it is subject to a risk of bleeding [28]. Furthermore, regarding the prescription of the dosage of VKAs, the global landscape is very varied. In fact, VKAs can be administrated either by a specialized surveillance center or by general practitioners or other specialists, such as cardiologists or internists. Naturally, this variability in VKA administration could affect the success and the safety of the anticoagulant therapy. Several studies seem to demonstrate a better therapeutic management in patients undergoing local control of PT/INR compared to centralized control $[29,30]$. The aim of the present study was to evaluate the event rates of several clinical composite outcomes, such as bleeding, venous thromboembolic events, and all-cause death, comparing three organizational models 


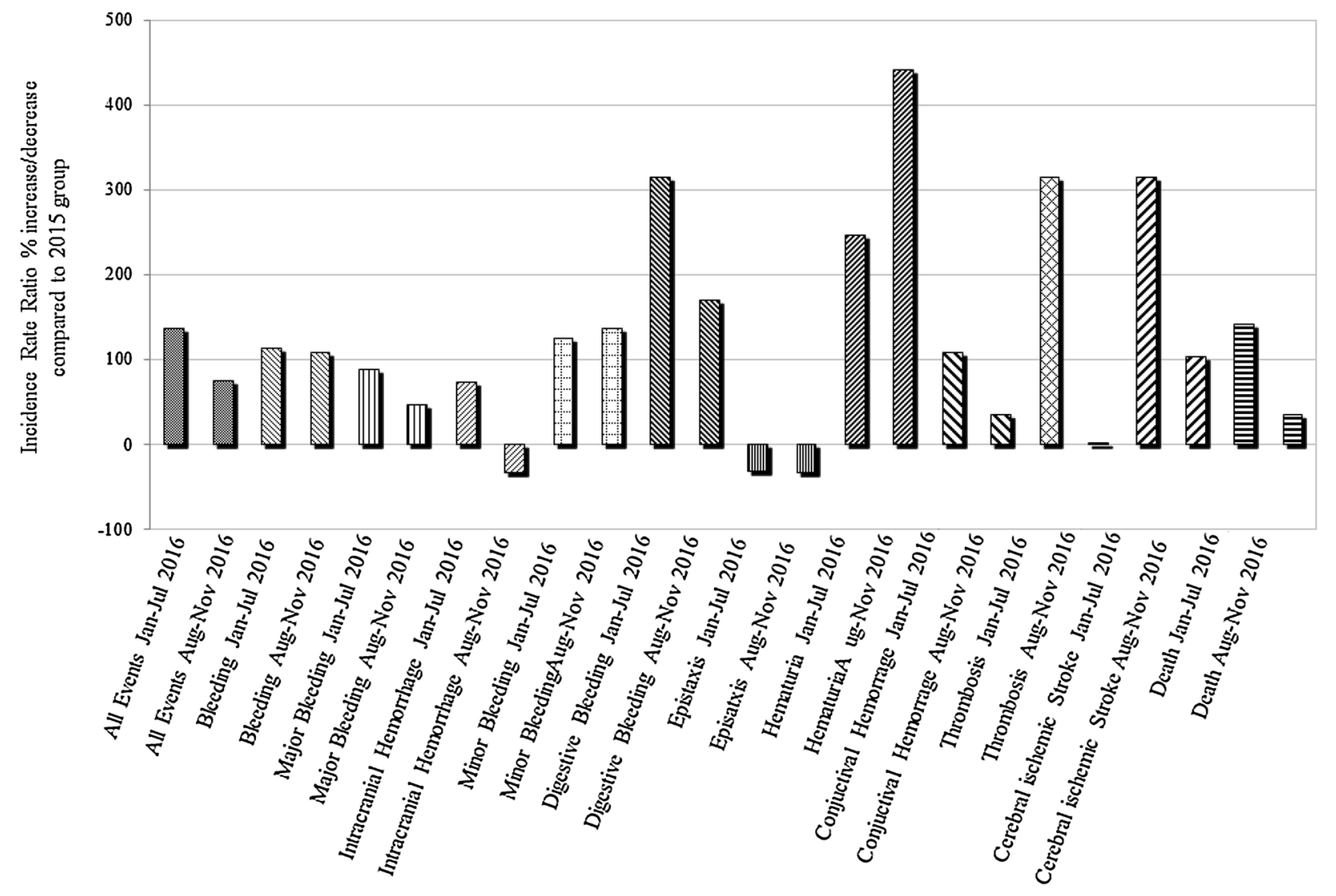

Fig. 3 Percentage increase/decrease of the incidence rate ratio among the several analytical management models. The 2016 groups, Jan-Jul and Aug-Nov, were compared to the 2015 group

on the basis of the analytical patient management. Specifically, from 1 January to 31 December 2015 the analytical management of patients treated with VKAs was under the direct responsibility of the surveillance center of Chieti, Italy. After a hospital reorganization in the management of patients undergoing anticoagulant therapy from 15 January to 15 July 2016, the surveillance center had only the ability to view the PT/INR results, without the possibility to perform the tests and to evaluate the internal and external quality controls and without the possibility to monitor, in real time, all laboratory analyses of the patients (e.g., many parameters, such as serum creatinine, transaminases, hemoglobin, platelets, are most important in order to perform a correct anticoagulant therapy minimizing the risks inherent to the therapy itself). Subsequently, access was given to the laboratory information system between
15 August and 15 November, and patients underwent a third organizational model, in which the surveillance center had the possibility to monitor all laboratory analyses, but without the capacity to perform the PT/INR tests and to evaluate the internal and external controls. The primary endpoint of the study, therefore, was to evaluate the incidence rates of several clinical composite outcomes as follows: bleeding, venous thromboembolic events, and all-cause death. The results showed a significant rise of the incidence rate ratio in patients undergoing VKA treatment during the period 15 January-15 July 2016 compared to the previous one (2105 group) regarding bleeding, especially for minor bleeding and digestive bleeding; venous thromboembolic events; and all-death cause. In patients treated during the same period, thus with the same organizational model, we also evidenced an increase of the 


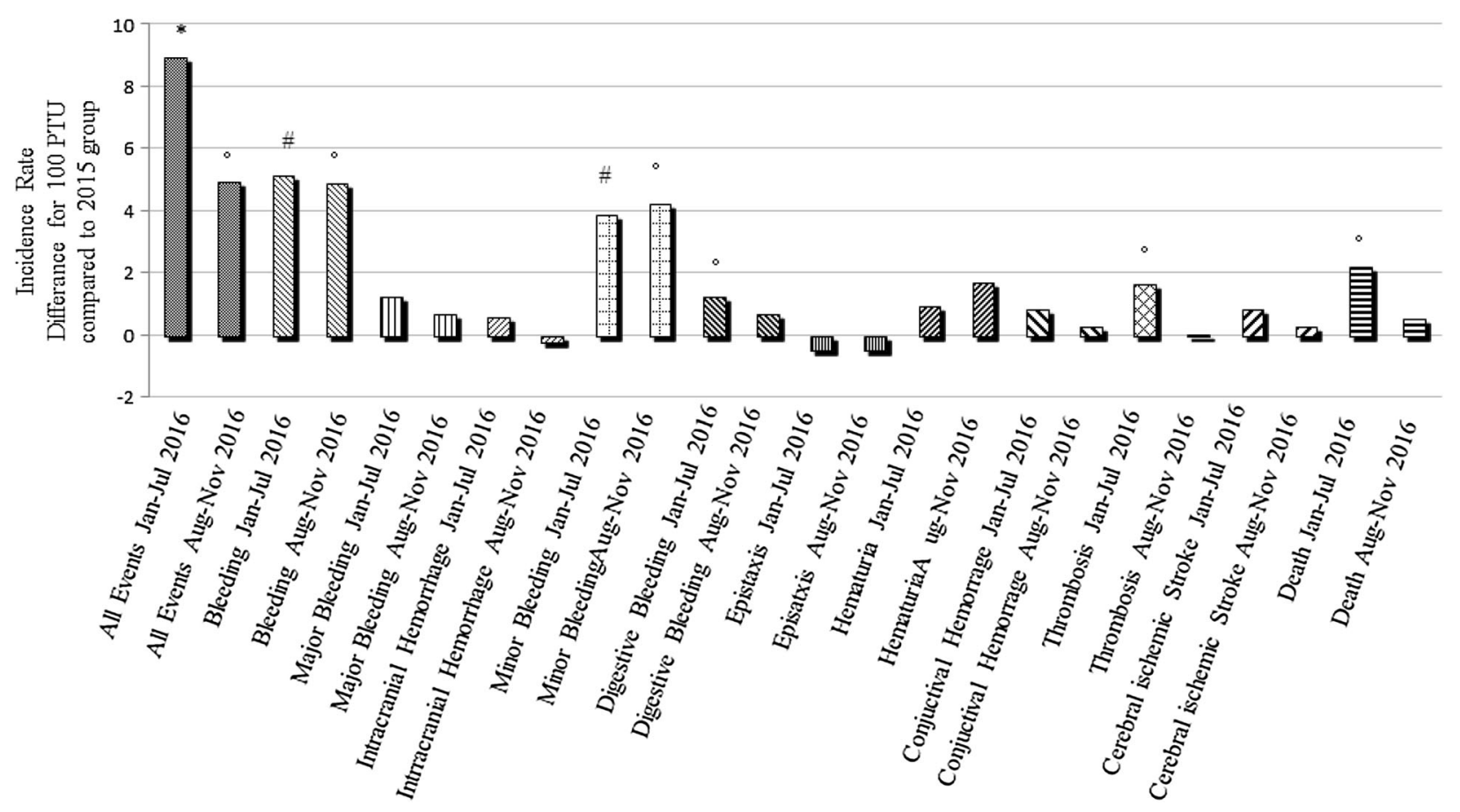

Fig. 4 Incidence rate difference calculated among the several organizational models. The 2016 groups, Jan-Jul and Aug-Nov, were compared to the 2015 group. These results evidence an increased risk of adverse events directly

incidence ratio concerning major bleeding, especially for the intracranial hemorrhage; minor bleeding, such as hematuria and conjunctival hemorrhage; and cerebral ischemic stroke that was about four times more frequent. Instead, a decreased incidence rate of epistaxis during the period 15 January-15 July 2016 compared to the previous one was evidenced. This point can be explained by one more year of VKA therapy and therefore of healthcare education for managing a very slight bleeding, such as epistaxis, without needing to consult the physicians of the surveillance center. Conversely, during the period Aug-Nov 2016 we observed a decrease in the incidence rate ratio concerning major bleedings, intracranial hemorrhages, digestive bleedings, venous thromboembolic events, cerebral ischemic strokes, and all-cause deaths $[34,35]$. In conclusion, we observed that the incidence rate of the minor bleedings, major bleedings, and venous thromboembolic events seems to be more influenced by the possibility to perform the PT/INR tests attributable to an organizational model that does not provide a direct analytical and clinical control by the surveillance center on patients undergoing VKA treatments. ${ }^{*} p<0.001 ;{ }^{\#} p<0.01 ;{ }^{\circ} p<0.05$

and by the ability to monitor all the laboratory analyses of the patients, respectively. In fact, the possibility for the surveillance center to directly control the PT/INR as well as internal and external quality controls, in order to minimize and correct casual and systemic laboratory errors, seems to explain the reason why patients, undergoing the 2016 treatment periods (Jan-Jul and Aug-Nov groups), showed worse results in terms of bleeding and thrombotic events as compared to the previous treatment period (2015 group), despite the same ranges of TTR. In addition, the incidence rate difference allowed one to quantify the percentage of the increased number of events attributable to the change in the organizational model. Furthermore, the calculated attributable risk showed the percentage of all event types that could be prevented just by using a management model in which all available analyses and clinical information were managed and controlled by the surveillance center. The outpatients care organization of the 


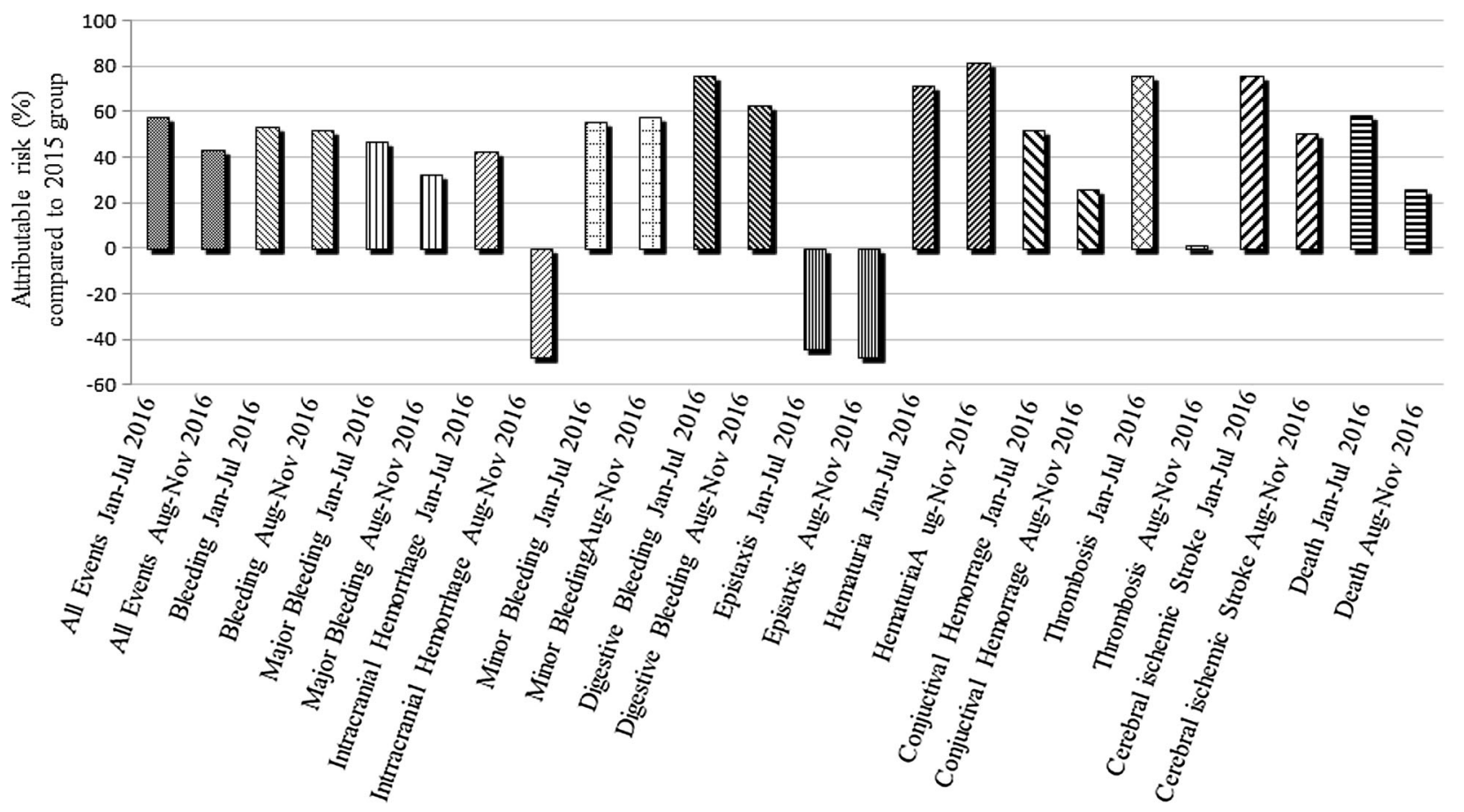

Fig. 5 Attributable risk calculated among the several organizational models. In this figure we compared the 2016 groups, Jan-Jul and Aug-Nov, to the 2015 group.

2015 treatment period led to the lowest clinical adverse events.

There are several limitations to this study. The change of the management of the PT/INR could have different effects on clinical outcomes. Varying lengths of times of observation could have affected the incidence of adverse events, and the physicians may increase the intensity of PT/INR monitoring, following an event.

\section{CONCLUSION}

This study highlighted that the organizational model of patients undergoing anticoagulant therapy could affect the clinical outcomes in a decisive way $[14,36,37]$. These findings showed that analytical and clinical data and information should be under the direct supervision and responsibility of the surveillance center. In fact, this approach seems to evidence the best results in terms of safety and therapeutic effectiveness.
These results show the percentage of the increased number of events attributable to the change in the organizational model

\section{ACKNOWLEDGEMENTS}

This project was partially funded by $60 \%$ Ateneo grants from Ministero dell'Università, Italy to S.M. and E.T. We also received partial contribution to research expenses by the Department of Medical, Oral and Biotechnologic Sciences, University of Chieti "G. d'Annunzio". No funding or sponsorship was received for article processing charges.

All named authors meet the International Committee of Medical Journal Editors (ICMJE) criteria for authorship for this manuscript, take responsibility for the integrity of the work as a whole, and have given final approval for the version to be published.

Disclosures. Vincenzo De Iuliis, Sebastiano Ursi, Gianfranco Vitullo, Irma Griffo, Antonio Marino, Marika Caruso, Francesco Cipollone, Sabrina Capodifoglio, Veronica Breda, Elena Toniato, Alfonso Pennelli, Pio Conti, and Stefano Martinotti have nothing to disclose. 
Compliance with Ethics Guidelines. Informed consent was given by patients whose retrospective data were used for this study. In addition, according to the guidelines of the Declaration of Helsinki for retrospective studies, we informed the university department where the experiments were conducted and the local ethics committee about the project.

Data Availability. The datasets during and/ or analyzed during the current study are available from the corresponding author on reasonable request. Tables and figures are original and have been produced by us for the purpose of this particular publication.

Open Access. This article is distributed under the terms of the Creative Commons Attribution-NonCommercial 4.0 International License (http://creativecommons.org/licenses/ by-nc/4.0/), which permits any noncommercial use, distribution, and reproduction in any medium, provided you give appropriate credit to the original author(s) and the source, provide a link to the Creative Commons license, and indicate if changes were made.

\section{REFERENCES}

1. Connolly SJ, Ezekowitz MD, Yusuf S, et al. Dabigatran versus warfarin in patients with atrial fibrillation. N Engl J Med. 2009;361:1139-51.

2. Patel MR, Mahaffey KW, Garg J, et al. Rivaroxaban versus warfarin in nonvalvular atrial fibrillation. N Engl J Med. 2011;365:883-91.

3. Granger $\mathrm{CB}$, Alexander $\mathrm{JH}$, McMurray JJ, et al. Apixaban versus warfarin in patients with atrial fibrillation. N Engl J Med. 2011;365:981-92.

4. Giugliano RP, Ruff CT, Braunwald E, et al. Edoxaban versus warfarin in patients with atrial fibrillation. N Engl J Med. 2013;369:2093-104.

5. AlTurki A, Proietti R, Birnie DH, Essebag V. Management of antithrombotic therapy during cardiac implantable device surgery. J Arrhythm. 2016;32(3):163-9.

6. Falk RH. Atrial fibrillation. $\mathrm{N}$ Engl J Med. 2001;344:1067-78.
7. Kasperska-Zajac A, Grzanka A, Kowalczyk J, et al. Refractory chronic spontaneous urticaria and permanent atrial fibrillation associated with dental infection: mere coincidence or something more to it? Int J Immunopathol Pharmacol. 2016;29(1):112-20.

8. Wipf JE, Lipsky BA. Atrial fibrillation. Thromboembolic risk and indications for anticoagulation. Arch Int Med. 1990;150:1598-1603.

9. Menke J, Luthje L, Kastrup A. Thromboembolism in atrial fibrillation. Am J Cardiol. 2010;105:502-10.

10. Steinberg BA, Piccini JP. Anticoagulation in atrial fibrillation. Br Med J. 2014;348:g2116.

11. Reynolds MW, Fahrbach K, Hauch O. Warfarin anticoagulation and outcomes in patients with atrial fibrillation: a systematic review and metaanalysis. Chest. 2004;126:1938-45.

12. Tidjane N, Hachem A, Zaid $\mathrm{Y}$, et al. A primary role for kinin B1 receptor in inflammation, organ damage, and lethal thrombosis in a rat model of septic shock in diabetes. Euro J Inflamm. 2015;13:40-52.

13. Schneider DJ, Sobel BE. Conundrums in the combined use of anticoagulants and antiplatelet drugs. Circulation. 2007;116:305-15.

14. Jia XF, Hong Z, Fan JH, Zhang YM. Clinical effect of mechanical fragmentation combined with recombinant tissue plasminogen activator artery thrombolysis on acute cerebral infarction. J Biol Regul Homeost Agents. 2016;30(3):821-6.

15. Fang Y, Zong HL, Zhang L, Wang ZH, Sun LM, Zhang RF. Vena-venous hemofiltration in treating severe injury-induced multiple organ dysfunction syndrome. J Biol Regul Homeost Agents. 2016;30(2):477-84.

16. Mallouppas M, Vassiliou V. Anticoagulation for atrial fibrillation: is this the end of warfarin? Not just yet. J Angiol. 2013. doi:10.1155/2013/874827

17. January CT, Wann LS, Alpert JS. AHA/ACC/HRS guideline for the management of patients with atrial fibrillation: executive summary. J Am Coll Cardiol. 2014;64:2246-80.

18. CAST (Chinese Acute Stroke Trial) Collaborative Group. CAST: randomized placebo-controlled trial of early aspirin use in 20,000 patients with acute ischaemic stroke. Lancet. 1997;349(9066):1641-9.

19. Mascali A, Franzese O, Nisticò S, et al. Obesity and kidney disease: beyond the hyperfiltration. Int J Immunopathol Pharmacol. 2016;29(3):354-63. 
20. Piotrowska Ż, Janiuk I, Lewandowska A, Kasacka I. Decreased immunoreactivity of visfatin in the pancreas and liver of rats with renovascular hypertension. J Biol Regul Homeost Agents. 2016;30(4):1073-8.

21. Crincoli V, Ballini A, Fatone L, Di Bisceglie MB, Nardi GM, Grassi FR. Cytokine genotype distribution in patients with periodontal disease and rheumatoid arthritis or diabetes mellitus. J Biol Regul Homeost Agents. 2016;30(3):863-6.

22. Mahmoud MH, Badr G, El Shinnawy NA. Camel whey protein improves lymphocyte function and protects against diabetes in the offspring of diabetic mouse dams. Int J Immunopathol Pharmacol. 2016;29(4):632-46.

23. Bianchi E, Ripandelli G, Taurone S, et al. Age and diabetes related changes of the retinal capillaries: an ultrastructural and immunohistochemical study. Int J Immunopathol Pharmacol. 2016;29(1):40-53.

24. Adar T, Edden Y, Shteingart S, et al. Portal hypertension is associated with modulation of regulatory T cells. Eur J Inflamm. 2016;14:40-47.

25. Rietbrock S, Heeley E, Plumb J. Chronic atrial fibrillation: incidence, prevalence, and prediction of stroke using the congestive heart failure, hypertension, age $>75$, diabetes mellitus, and prior stroke or transient ischemic attack (CHADS2) risk stratification scheme. Am Heart J. 2008;156:57-64.

26. Lip GY, Nieuwlaat R, Pisters R. Refining clinical risk stratification for predicting stroke and thromboembolism in atrial fibrillation using a novel risk factor-based approach: the euro heart survey on atrial fibrillation. Chest. 2010;137:263-72.

27. Olesen JB, Lip GY, Hansen ML. Validation of risk stratification schemes for predicting stroke and thromboembolism in patients with atrial fibrillation: nationwide cohort study. $\mathrm{Br}$ Med J. 2011;342:d124.

28. Mant J, Hobbs FD, Fletcher K. Warfarin versus aspirin for stroke prevention in an elderly community population with atrial fibrillation (the Birmingham Atrial Fibrillation Treatment of the Aged Study, BAFTA): a randomised controlled trial. Lancet. 2007;370:493-503.
29. Arbring K, Uppugunduri S, Lindhal TL. Comparison of prothrombin time (INR) results and main characteristics of patients on warfarin treatment in primary health care centers and anticoagulation clinics. BMC Health Serv Res. 2013;7(13):85.

30. Wieloch M, Själander A, Frykman V, Rosenqvist M, Eriksson N, Svensson PJ. Anticoagulation control in Sweden: reports of time in therapeutic range, major bleeding, and thrombo-embolic complications from the national quality registry AuriculA. Eur Heart J. 2011;32(18):2282-9.

31. Wysowski DK, Nourjah P. Bleeding complications with warfarin use: a prevalent adverse effect resulting in regulatory action. Arch Int Med. 2007;167:1414-9.

32. Molteni M, Cimminiello C. Warfarin and atrial fibrillation: from ideal to real the warfarin affaire. Thromb J. 2014;12:5.

33. Chow S, Shao J, Wang H. Sample size calculations in clinical research, 2nd ed. Boca Raton: Chapman $\&$ Hall/CRC Biostatistic Series.

34. Schulman S, Kearon C, Subcommittee on Control of Anticoagulation of the Scientific Standardization Committee of the International Society on Thrombosis and Haemostasis. Definition of major bleeding in clinical investigations of antihemostatic medicinal products in non-surgical patients. J Thromb Haemost. 2005;3:692-4.

35. Atarashi $\mathrm{H}$, Inoue $\mathrm{H}$, Okumura $\mathrm{K}$, Yamashita $\mathrm{T}$, Origasa $\mathrm{H}$. Investigation of optimal anticoagulation strategy for stroke prevention in Japanese patients with atrial fibrillation: the J-RHYTHM Registry study design. J Cardiol. 2011;57:95-9.

36. Chuai JB, Shi L, Ma XY, Wu D, Kang K, Jiang SL. Curative effect of mechanical heart valve replacement and anticoagulant therapy after surgery. J Biol Regul Homeost Agents. 2016;30(1):141-6.

37. Yang F, Xiang ML, Liu YM. Thrombin in combination with intensive nursing in treating upper gastrointestinal bleeding in children. J Biol Regul Homeost Agents. 2016;30(2):491-5. 